\title{
Effect of education on wellbeing among high school students in a poor rural zone of Yucatan, Mexico
}

\author{
Patricia Elena Rivas Dawn \\ Plantel Cutzama 04. \\ COBAY \\ Cutzama, Yucatan Mexico
}

\author{
Heriberto Emilio Cuanalo de la Cerda, \\ Julia Elena Fraga Berdugo \\ Department of Human Ecology \\ Cinvestav Merida \\ Merida, Yucatan., Mexico
}

\begin{abstract}
Education provides the opportunity to overcome poverty and attain greater wellbeing. An evaluation was done of the impact of education - understood as formation of knowledge, values and attitudes - on wellbeing in high school students in a poor rural zone of Yucatan, Mexico. A total of 223 (94 women, 129 men) students from 14 to 19 years of age answered an instrument covering two wellbeing dimensions: eating habits and self-concept. Statistical analyses of their answers showed education to have an effect only in some aspects of eating habits. Differences by sex were present in both eating habits and selfconcept, and age affected only self-concept. The education offered these students had only a minimal effect on improving their wellbeing, undermining one of the overarching purposes of education.
\end{abstract}

Keywords-Education, high school, wellbeing, poverty

\section{INTRODUCTION}

\section{A. Education}

Education is perceived as an opportunity to overcome poverty and attain greater wellbeing [1]; [2]; [3]; [4]. Its main purpose is to generate integral development that encompasses knowledge, values and attitudes which help in addressing the challenges of life. Education currently emphasizes personal development and wellbeing rather than the mere formation of human capital for economic production [5]; [6]. This educational approach focuses on student learning, respect, active participation, creativity, collaborative work, responsibility, pro-social behavior and human development [7]. In other words, education goes beyond mere instruction and includes promoting a variety of knowledge types, skills, values and attitudes required to successfully deal with daily challenges, communicate effectively, resolve problems and challenges, and plan a better future [8]; [9]. Indeed, the Economic Commission for Latin America and the Caribbean [10], states education to be one of the most important mechanisms available to states to reverse the intergenerational reproduction of inequality and disassociate individuals' social origins from their accomplishments in terms of wellbeing.

Education increases a person's ability to make informed decisions and avoid diverse types of risk [10]. It also promotes development of confidence and sociability, which are related to social participation and employment [1]. In addition, it generally encourages complete human development by helping in the formation of the competences, knowledge and values that make for a better life [11].

Confronting and overcoming poverty in Mexico requires that its population develop their skills and talents [12], a goal that can be attained through integral education for life. In a study of the effects of basic education on poverty in rural Mexico, students who finished elementary and junior high education were less likely to become poor, suggesting that education in and of itself is an effective instrument for overcoming poverty in Mexico[4].

Education is a vital factor for overcoming poverty, however, it is not the only one that requires attention if poverty in Mexico is to be diminished. Other factors such as democracy, peace, public heath, increasing production and productivity aimed at developing local and regional markets, and access to efficient savings and loans systems are equally as important. All these factors interact in complex ways, and need to be considered both as a whole and individually. Education is fundamental in the fight against poverty and to attaining greater individual wellbeing. A proper education should broaden employment options and improve life style, thus increasing access to opportunities in a society. Acquiring an education helps people to overcome poverty and reduces social inequality.

\section{B. Poverty}

Poverty constitutes a huge obstacle to development in Mexico, Latin America and the world. It is associated with a lack of sufficient resources to meet basic human needs such as food, health, shelter, clothing and education, among others. Living in poverty limits development of human potential, the opportunity for advancement, and the possibility of attaining an acceptable level of wellbeing [13]. If poverty is defined as a condition of lack or need of elements indispensable for life [14], then people are poor because they do not have what they need or chronically lack the resources required to access what they need. The distinction between desire and need is often confused, although they clearly contrast: a need is indispensable while a desire is a predilection for things that may or may not be essential [15]. A need is something 
required by an organism to live and experience wellbeing, whereas every desire does not imply a need. For something to qualify as a need it must directly contribute to sustaining an individual's existence and wellbeing [16]. Human needs are few, finite and classifiable, and do not differ across cultures or throughout human history. What does change is the means used to meet needs within any given culture or time period [17]. Therefore, in its most basic sense poverty is discordance between needs and satisfiers.

Poverty is no longer perceived as a o ne-dimensional concept - a lack of resources [18] - but is now defined as multidimensional because it manifests in various ways: lack of sufficient resources to ensure subsistence; the presence of hunger and malnutrition; presence of disease; limited access to education and other basic services; increased mortality from illness; precarious households and unsafe environments; and limited participation in civic, social and cultural life. A multidimensional view of poverty considers three interacting aspects: limited opportunities; vulnerability; and social exclusion [19].

Mexico faces a d aunting degree of poverty and income distribution inequality [4]. Rural areas suffer higher levels of inequality and more acute poverty [4]. The National Council for Evaluation of Social Development Policy (CONEVAL) [20] addresses multidimensional poverty using three dimensions: economic wellbeing; social rights; and territorial context. A person suffers multidimensional poverty when at least one of his/her social development rights is not guaranteed and her/his income is insufficient to acquire the goods and services required to meet his/her needs. Extreme multidimensional poverty is when three or more deficiencies are present and income is insufficient to acquire a basic food basket.

Mexico's south and southeast have the highest poverty rates in the country. For example, the indigenous Mayan community of Yaxcabá, Yucatan, has very high degrees of social underdevelopment and patrimony poverty, as well as high levels of food and skills poverty [20]. Poverty in Yaxcabá is manifest in many ways, including low personal self-esteem, lack of leadership, malnutrition and disease, low production and productivity, a lack of or very low wages, and high household vulnerability [21].

\section{Wellbeing}

Wellbeing is possession of what a human being needs to live a good life [22]. It is a complex concept that encompasses many dimensions (e.g. nutrition, self-esteem, education, etc.) of human life [23]. However, it is not a permanent condition of being or being well, but a dynamic process that changes in response to diverse factors which interact throughout a person's life, such as relationships with others and the environment, and distinct aspects of the individual, household, community and social environment [22].

Because wellbeing is evaluated through different domains of an individual's life, it is considered multidimensional. Reference [22] proposes wellbeing to consist of material, relational and subjective dimensions. The material dimension refers to aspects of physical wellbeing such as food, housing, environment, economic goods and income. The relational dimension refers to social aspects such as the norms and practices that control who obtains what and why, in other words, power, identity and interpersonal connections and differences. The subjective dimension refers to cultural values, ideologies and the conception people have of their situation. Interaction among these dimensions produces a condition of wellbeing which combines the circumstances and individuals' perceptions of them. Another way of stating this is that wellbeing is the combination of what a person has, what $\mathrm{s} / \mathrm{he}$ can do with that and his/her way of thinking about what $\mathrm{s} / \mathrm{he}$ has and can do with it [24]; [25]. This conception includes an objective facet, people's life conditions, and a subjective facet, what they think of these conditions and do in response to them. In a similar vein, [26] state that to accomplish true human development the perception of wellbeing must go beyond material goods, resources and social relations to include psychological conditions and subjective perceptions.

Within the condition of wellbeing there is an interaction between factors internal to the person (e.g. ideas, interests, psychological aspects, among others) and external (physical, social and family environments); both types influence whether or not a p erson has a $g$ ood life. Among these factors is poverty, which affects various dimensions of wellbeing, not just those depending on material conditions. Of course, poverty limits many material aspects of wellbeing, but it also limits access to an adequate food supply, good health, education, and better housing conditions, as well as very personal aspects such as self-concept, motivations, goal establishment, interpersonal relations, health practices and emotions, among others [14]; [13]; [24].

Research on dimensions of wellbeing in adolescents includes indicators such as academic achievement, time use, health, self-esteem, family, friends, sports, poverty, parents' income and family structure [27]; [28]. Other studies include dimensions such as affection, status, ability to face problems, safety and interpersonal relations, among others [29]; [30]; [31]. In the present study, two indicators relevant to local conditions were chosen: how their actions are linked to eating habits and estimates of how individuals perceive their wellbeing and what they do in response to it (Self-concept).

Eating habits. Eating habits formed during childhood and adolescence are highly likely to last throughout life. If they are damaging, they will have serious negative consequences on future health and wellbeing [32]. Problems with nutrition are frequently related to low fruit and vegetable intake, frequent consumption of high energy foods and deficiencies in certain nutrients [33]. Adolescent eating habits are influenced by a series of factors: individual and intrapersonal traits (biological and psychological); social and interpersonal environment (family and friends); environment or community (school, fast food availability); and macro-system or society (communication media, social and cultural norms) [34].

Mexico has one of the highest levels of bottled soft drink consumption in the world. Highly energetic, these displace the calories provided by healthier foods and are related to obesity and diabetes [35]. The foods available at school strongly influence students' food decisions and diet quality [36]. 
Self-concept. This constitutes the foundation for many human behaviors and is therefore an important dimension of personal wellbeing. Self-concept is defined as the perception a person has of her/himself, and tends to have profound effects on a person's thinking process, emotions, behaviors, desires, values and objectives [37]. It can be reflected in scholastic success or failure, social and work relations, stress management, locus of control strategies, the ability to attain emotional adjustment, adaption level, assertiveness and personal satisfaction, among others-

Construction of adolescent self-concept is influenced by the surrounding social, academic, emotional, family and physical environments. As a result, development of adolescent wellbeing depends on a s eries of factors in the home (e.g. educational style, upbringing, family environment, emotional support, affection received), and school (e.g. values, discipline, relationships with other students and teachers, academic accomplishments) [38].

The main purpose of education is to generate integral development of humans, encompassing knowledge, values and attitudes. Education is a fundamental factor in addressing the challenges of life in general, and of combating poverty in the case of a school in a poor area. We estimated the impact of education on high school students in first-, second- and thirdyear groups by statistically comparing changes between three years in eating habits and self-concept, both of which have and continue to have an effect on wellbeing.

\section{METHOD}

The study population was the student body of a high school in the community of Yaxcabá belonging to the Yucatan State High School system (Colegio de Bachilleres del Estado de Yucatán - COBAY). This school was chosen for being the highest level school in the Yaxcabá municipality and because it receives students from the different towns in the municipality. Data were collected for 223 students aged 14 to 19 years (average $=16$ years), of which $94(42.2 \%)$ were women and $129(57.8 \%)$ men. The students were studying the first $(n=77)$, third $(n=73)$ and fifth $(n=73)$ semesters of a six-semester high school curriculum.

Located in the south central portion of Yucatan, the community of Yaxcabá ("Place of green earth" in Maya) is the seat of one of the poorest municipalities in the state [20]. Its 14,802 inhabitants suffer a very high degree of marginalization and a high degree of social underdevelopment [39].

\section{A. Instrument}

The instrument applied to the study population included two sections, each addressing a dimension of wellbeing: eating habits; and self-concept.

Eating habits. This section was a list of ten foods (e.g. bottled soft drinks, natural juices, candy, lunch, etc.) consumed by the students during the week prior to instrument application.

Self-concept. This section evaluated the multidimensional image people have of themselves, and was validated for
Mexican subjects from 14 to 48 years of age. Forty-four adjectives were grouped into nine factors, all but one containing five adjectives each. Responses were made on a seven-point scale, in which progressively larger response boxes closer to the adjective meant this adjective better described the subject whereas smaller boxes further from the adjective indicated the contrary. The first of the self-concept factors was social expression, including positive characteristics which allowed the individual to communicate and express her/himself. Second was the ethical normative factor, constituting a series of characteristics demonstrating congruence with social-personal values that reflect cultural mandates. Social-emotional intelligence was the third and comprised an equable, flexible social-emotional way of facing interpersonal relations and life problems. Passive-negative external control was the fourth and involved negative characteristics demonstrating an inability and lack of interest in acting constructively vis-à-vis the environment. The fifth factor was social-affiliative and addressed positive interindividual feelings experienced by the subject in which the other person was the object of nearness and affection. The sixth was emotional-negative self-affirmative and focused on negative temperament characteristics that imply dissatisfaction, impulsiveness and emotional excitement. Constructive tools were seventh and covered characteristics reflecting functionality and abilities in different ambits (work, home, school, etc.). Eighth was emotional vulnerability, which addressed negative moods experienced by the subject typified by indifference, dislike and vulnerability. Finally, the ninth factor contained adjectives suggestive of depression and indicative of declining emotional health, such as negative characteristics implying nostalgia and alteration [37].

\section{B. Procedures}

A pilot test was done by applying the instrument's eating habits section to one of the three first semester student groups. We assumed that there were no important differences between the different semester groups since all are from similar backgrounds. Changes were made based on the results and the instrument applied to two groups each of first, third and fifth semester students. It was made clear to all groups that the instrument was completely anonymous and students were only asked to provide their age in years, gender and semester.

\section{Analysis}

Means for the data were compared with a one-way analysis of variance (ANOVA) and a Student $t$ test run for two independent samples. A factorial analysis was run to estimate self-concept factor validity and the Cronbach alpha coefficient calculated to estimate factor reliability. All analyses were done with the SPSS ver. 17.0 statistics package.

Before comparing means for the self-concept factors, the factorial analysis and Cronbach alpha coefficient were run to confirm that the nine factors were valid and reliable in the studied population at levels reported by the instrument designers [39]. This ensured instrument applicability in this population. Factor significance was determined using the KMO (Kaiser-Meyer-Olkin) index with a Bartlett sphericity test. A low KMO $(\leq 0.5)$ indicates low variable correlation and 
an inappropriate factorial analysis since almost as many variables as factors would be needed. Higher KMO $(>5)$ values indicate sufficient variable correlation and that the factorial analysis is technically useful. The Bartlett test is based on the null hypothesis (Ho: no correlation between variables) and the alternative hypothesis (H1: that they are correlated at a significance equal to or less than $5 \%(\boldsymbol{p} \leq 0.05)$. Rejection of the Ho indicates that correlation exists between the variables.

Comparisons between semesters, sexes and ages were made within eating habits and self-concept wellbeing dimensions with a means comparison by group using an ANOVA and a Student $\mathrm{t}$ test, both at a $5 \% \quad(p \leq 0.05)$ significance level. All 223 cases were used to calculate the effects of semester (first semester $=77$ students, third $=73$, fifth $=73$ ) and sex (94 women, 129 men). For age, the effect was estimated using only 216 cases $(15$ years $=55,16=59$, $17=83,18=19)$, eliminating ages with very few cases $(14$ years $=3,19=4)$.

A comparison of means was done using the null hypothesis Ho: $\mu 1=\mu 2=\mu 3=\ldots \mu_{n}(n=3$, for semesters; $n=2$ for sex and $\mathrm{n}=4$ for ages) and the alternative hypothesis $\mathrm{H} 1$ : $\mu 1 \neq \mu 2 \neq \mu 3 \neq \ldots \mu_{\mathrm{n}}$ was rejected if the $p$ was less than or equal to $5 \% \quad(p \leq 0.05)$, meaning there was difference between the means of the groups. A variance homogeneity test was done using the Levene statistic with a 5\% significance level. A large number of variables exhibited variance heterogeneity, so the Tamhane T2 a posteriori test was applied to the independent variables of self-concept and age at a $5 \%$ significance level $(p \leq 0.05)$. Sex has only two states for the independent variable so the Student $\mathrm{t}$ test was used under the assumption of variance heterogeneity at a $5 \%$ significance level $(\boldsymbol{p} \leq 0.05)$.

\section{RESULTS}

\section{A. Instrument Validity and Reliabilit}

The self-concept instrument was validated using KMO values ranging from 0 to 1 . All nine self-concept factors had values higher than 0.59 and several near 1.0 (social expressive $=0.815 ;$ ethical normative $=0.817 ;$ social-emotional intelligence $=0.702$; negative-passive internal control $=0.780$; social-affiliative $=0.834$; emotive-negative self-affirmation $=$ 0.662 ; constructive tool $=0.795$; emotional vulnerability $=$ 0.701 ; depressive $=0.600$ ). The Bartlett sphericity test showed significant $(p=0.00)$ correlation between variables in each factor. Both the KMO and Bartlett test values for the factors confirmed that the self-concept instrument was valid for the studied population and that factorial analysis was an adequate technique.

Instrument reliability for the studied population was corroborated by high Cronbach alpha values for each factor (social expressive $\alpha=0.79$; ethical normative $\alpha=0.80$; socialemotional intelligence $\alpha=0.68$; negative-passive external control $\alpha=0.75$; social-affiliative $\alpha=0.85$; emotive-negative self-affirmative $\alpha=0.55$; constructive tool $\alpha=.73$; emotional vulnerability $\alpha=0.60$; and depressive $\alpha=0.52$ ).

\section{B. Eating habits}

Differences were observed between semesters for consumption of bottled soft drinks, ice cream and shave ice, and fried snacks. By sex, differences were present for all but water intake, and by age the only difference was for natural juice intake (TABLE 1).

Bottled soft drink, ice cream and shave ice, and fried snack consumption mean values and significance levels are shown in TABLES 2, 3 and 4. First semester students reported consistently consuming more of the listed food types than those in third and fifth semesters.

Between sexes, men exhibited a higher mean food intake than women, even in terms of water, for which they did not differ (TABLE 5). The overall higher food intake of men observed here can largely be explained by their higher energy requirements [41]. Another factor affecting these figures may be differences in food choice. In a study of food choice (fats, fruits, fiber and salt) among university students in 23 countries, it was reported that women tended to avoid high-fat food, ate fiber-rich foods, more fruit and less salt than men [42]. These choices also reflect the fact that women are more aware of their health than men and that they are more likely to put their attitudes towards health into practice. Women have the added advantage of more frequently being involved in food purchase and preparation, providing them the opportunity to choose healthier foods.

TABLE $1 \quad$ Differences in eating habits by semester (Fisher, F), sex (Student, T) and age (Fisher) and their $\boldsymbol{p}$ values,

\begin{tabular}{l|cc|cc|cc}
\hline \multirow{2}{*}{ Foods } & \multicolumn{3}{|c}{ Semester } & \multicolumn{2}{c}{ Sex } & \multicolumn{2}{c}{ Age } \\
\cline { 2 - 7 } & $\mathrm{F}$ & $\boldsymbol{p}$ & $T$ & $\boldsymbol{p}$ & $\mathrm{F}$ & $\boldsymbol{p}$ \\
\hline 1. Bottled soft drinks & $\mathbf{4 . 7 8 4}$ & $\mathbf{0 . 0 0 9}$ & $\mathbf{- 5 . 5 3 9}$ & $\mathbf{0 . 0 0 0}$ & 1.103 & 0.349 \\
(ml) & & & & & & \\
2. Water (ml) & 1.337 & 0.265 & -1.191 & 0.235 & 0.243 & 0.866 \\
3. Natural juice (ml) & 1.370 & 0.256 & $\mathbf{- 2 . 3 7 7}$ & $\mathbf{0 . 0 1 8}$ & $\mathbf{2 . 7 9 8}$ & $\mathbf{0 . 0 4 1}$ \\
4. Ice creams (unit) & $\mathbf{4 . 0 5 4}$ & $\mathbf{0 . 0 1 9}$ & $\mathbf{- 3 . 2 6 6}$ & $\mathbf{0 . 0 0 1}$ & 0.904 & 0.440 \\
5. Cookies (bag) & 0.365 & 0.694 & $\mathbf{- 2 . 4 8 1}$ & $\mathbf{0 . 0 1 4}$ & 1.970 & 0.119 \\
6. Fried snacks (bag) & $\mathbf{5 . 9 0 6}$ & $\mathbf{0 . 0 0 3}$ & $\mathbf{- 2 . 3 6 9}$ & $\mathbf{0 . 0 1 9}$ & 1.651 & 0.179 \\
7. Candy (unit) & 1.201 & 0.303 & $\mathbf{- 2 . 1 7 6}$ & $\mathbf{0 . 0 3 1}$ & 0.617 & 0.604 \\
8. Natural snacks & 1.220 & 0.297 & $\mathbf{- 2 . 6 3 3}$ & $\mathbf{0 . 0 0 9}$ & 0.879 & 0.453 \\
9. Fast food (unit) & 1.430 & 0.242 & $\mathbf{- 3 . 7 2 7}$ & $\mathbf{0 . 0 0 0}$ & 0.273 & 0.845 \\
10. Appetizers (unit) & 0.970 & 0.381 & $\mathbf{- 2 . 3 8 8}$ & $\mathbf{0 . 0 1 8}$ & 0.609 & 0.610 \\
\hline
\end{tabular}

TABLE 2. Means for bottled soft drink intake $(\mathrm{ml})$ by semesters with $\boldsymbol{p}$ values (Tamhane).

\begin{tabular}{ccccc}
\hline Semester & Mean & \multicolumn{3}{c}{$\boldsymbol{p}$} \\
\cline { 3 - 5 } & & 1 & 3 & 5 \\
\hline 1 & 1637 & & 0.166 & $\mathbf{0 . 0 0 7}$ \\
3 & 1344 & & & 0.624 \\
5 & 1180 & & & \\
\hline
\end{tabular}

TABLE 3. Means for ice cream and shave ice intake (units) by semesters with $\boldsymbol{p}$ values (Tamhane).

\begin{tabular}{|c|c|c|c|c|}
\hline \multirow[t]{2}{*}{ Semester } & \multirow[t]{2}{*}{ Mean } & \multicolumn{3}{|c|}{$p$} \\
\hline & & 1 & 3 & 5 \\
\hline 1 & 2.23 & & 0.698 & 0.004 \\
\hline 3 & 1.86 & & & 0.243 \\
\hline 5 & 1.27 & & & \\
\hline
\end{tabular}


TABLE 4. values (Tamhane).

\begin{tabular}{|c|c|c|c|c|}
\hline \multirow[t]{2}{*}{ Semester } & \multirow[t]{2}{*}{ Mean } & \multicolumn{3}{|c|}{$p$} \\
\hline & & 1 & 3 & 5 \\
\hline 1 & 3.39 & & 0.346 & $\overline{0.001}$ \\
\hline 3 & 2.77 & & & 0.188 \\
\hline 5 & 2.12 & & & \\
\hline
\end{tabular}

TABLE 5.

Mean food intake values for women and men.

\begin{tabular}{|l|r|r|}
\hline Foods & Women & Men \\
\hline 1. Bottled soft drinks (ml) & 1023.40 & 1660.80 \\
\hline 2. Water (ml) & 3173.46 & 3654.65 \\
\hline 3. Natural juice (ml) & 735.15 & 1150.00 \\
\hline 4. Ice creams (unit) & 1.30 & 2.16 \\
\hline 5. Cookies (bag) & 1.09 & 1.67 \\
\hline 6. Fried snacks (bag) & 2.36 & 3.07 \\
\hline 7. Candy (unit) & 1.51 & 2.57 \\
\hline 8. Natural snacks & 1.84 & 2.78 \\
\hline 9. Fast food (unit) & 3.21 & 4.72 \\
\hline 10. Appetizers (unit) & 3.54 & 5.07 \\
\hline
\end{tabular}

Natural juice consumption differed between ages, however, the variance heterogeneity between ages caused this significance to be lost when the Tamhane test was applied.

\section{Self-concept}

No differences by semester were observed in any of the self-concept factors, indicating that the educational process failed in augmenting student self-value (TABLE 6). Differences were observed by sex for five of the nine factors, highlighting the strength of male/female role models and traditions in the culture and the minimum impact semester has had on these.

TABLE $6 . \quad$ Differences in self-concept factors by semester (Fisher, F), sex (Student, $\boldsymbol{t}$ ) and age (Fisher) and its $\boldsymbol{p}$ values.

\begin{tabular}{l|cc|cc|cc}
\hline \multirow{2}{*}{ Self-concept Factors } & \multicolumn{2}{|c|}{ Semester } & \multicolumn{2}{c|}{ Sex } & \multicolumn{2}{c}{ Age } \\
\cline { 2 - 7 } & $\mathrm{F}$ & $\boldsymbol{p}$ & $\boldsymbol{t}$ & $\boldsymbol{p}$ & $\mathrm{F}$ & $\boldsymbol{p}$ \\
\hline 1.Social Expressive & 0.970 & 0.381 & 1.748 & 0.082 & 0.664 & 0.575 \\
2.Ethical Normative & 0.763 & 0.467 & $\mathbf{2 . 1 3 0}$ & $\mathbf{0 . 0 3 4}$ & 1.240 & 0.296 \\
3. Social Emotional & 2.817 & 0.062 & $\mathbf{- 0 . 4 2 5}$ & 0.671 & $\mathbf{3 . 2 2 9}$ & $\mathbf{0 . 0 2 3}$ \\
Intelligence & & & & & & \\
4. Negative-Passive & 1.590 & 0.206 & $\mathbf{- 3 . 8 5 9}$ & $\mathbf{0 . 0 0 0}$ & 0.480 & 0.697 \\
External Control & & & & & & \\
5. Social-Affiliative & 0.840 & 0.433 & $\mathbf{3 . 3 3 9}$ & $\mathbf{0 . 0 0 1}$ & 1.016 & 0.387 \\
6. Emotive-Negative & 0.272 & 0.762 & $\mathbf{- 4 . 7 2 1}$ & $\mathbf{0 . 0 0 0}$ & 1.798 & 0.149 \\
Self-Affirmative & & & & & & \\
7. Constructive Tool & 0.593 & 0.553 & 0.070 & 0.945 & 1.563 & 0.199 \\
8. Emotional & 0.708 & 0.468 & $-\mathbf{- 2 . 6 2 8}$ & $\mathbf{0 . 0 0 9}$ & 1.744 & 0.159 \\
Vulnerability & & & & & & \\
9. Depressive & 1.829 & 0.163 & -0.110 & 0.913 & 2.291 & 0.079 \\
\hline
\end{tabular}

Women had higher mean values than men in the ethicalnormative and social-affiliative factors (TABLE 7), suggesting that they perceived themselves as more honest, honorable, decent, loyal and respectable, as well as more romantic, tender, sentimental, loving and caring. In contrast, the men had higher mean values in the negative-passive external control, emotive-negative self-affirmative and emotional vulnerability factors. This implies that they perceived themselves as more inept, frustrated, false, undesirable and pessimistic; conflictive, unreliable, dominant, temperamental and irritable; as well as solitary, apathetic, timid and volatile. These differences by sex are similar to those reported in a study done of 2,270 subjects between 14 and 48 years of age in Mexico and using the same self-concept instrument [37].

TABLE 7. Means values of significantly different factors (Tamhane) between woman and men.

\begin{tabular}{lll}
\hline \multicolumn{1}{c}{ Factors } & Women & Men \\
\hline 1.Ethcial Normative & $\mathbf{5 . 8 7}$ & 5.58 \\
2. Negative-Passive External Control & 2.57 & $\mathbf{3 . 2 1}$ \\
3. Social-Affiliative & $\mathbf{6 . 0 2}$ & 5.55 \\
4. Emotive-Negative Self-Affirmative & 3.38 & $\mathbf{4 . 0 2}$ \\
5. Emotional Vulnerability & 3.16 & $\mathbf{3 . 5 7}$ \\
\hline
\end{tabular}

Only the social emotional intelligence factor exhibited differences in the age variable, and only between students aged 15 and those aged 17 years (TABLE 8). There was an overall tendency to increase with age, with a slight decline at 18 years of age, meaning that with age the students generally perceived themselves as calmer, more serene, peaceful, relaxed and stable [37].

TABLE 8. Social emotional intelligence factor means by ages with p values (Tamhane).

\begin{tabular}{l|l|llll}
\hline Age & \multirow{2}{*}{ Mean } & \multicolumn{4}{|c}{$\boldsymbol{p}$} \\
\cline { 3 - 6 } & & 15 & 16 & 17 & 18 \\
\hline 15 & 5.13 & & 0.963 & $\mathbf{0 . 0 5 0}$ & 0.344 \\
16 & 5.30 & & & 0.246 & 0.745 \\
17 & 5.64 & & & & 1.000 \\
18 & 5.61 & & & & \\
\hline
\end{tabular}

\section{DISCUSSION}

\section{A. Education level (Semesters)}

Quantified as semesters completed, education level was expected to influence student wellbeing, although differences were only observed in some of the eating habits variables. Education level and other variables are reported to affect student self-concept [43], [44], but no differences by semester were observed in the present data. This is probably a result of the education curriculum focusing primarily on instruction and only passingly addressing improved self-concept.

Fifth semester students were most aware of what they ate, but this does not confirm that education had influenced their healthy food choices. First semester students also consumed more bottled soft drinks, ice cream and shave ice, and fried snacks than more advanced students, indicating a general decrease in consumption of unhealthy foods. This also coincides with the personal care dimension results in which fifth semester students were more careful about what they ate. Education is not apparently responsible for this change. It is more likely due to improved organizational skills over time, which allowed the students to bring food from home rather than paying for the relatively expensive, low quality food available at the school. These results coincide with those reported in a s tudy of perceptions of the limiting and facilitating factors for healthy eating habits among adolescents (11 to 16 years of age) in the United States, Finland, the United Kingdom, Norway, Denmark and Australia [45]. The adolescents stated that the school did not offer healthy food alternatives and the teachers and education system in general provided little information and insufficient attention to the students in this area. 


\section{B. Sex}

Differences were observed in both eating habits and selfconcept.

Eating habits differed by sex for nine of the ten foods, with men having an overall higher intake than women. Men are normally heavier than women, expend more energy and therefore require more food intake [41]. Eating habits are also influenced by cultural aspects such as beliefs, daily practices, family, social influence, friends, school and communication media. Women, for example, tend to be more concerned about body image than men, causing them to eat smaller amounts of food, and men are perceived to work harder and thus require more food [41].

Compared to the men, the women's self-concept results exhibited characteristics more congruent with their personal values and cultural expectations, as well as more positive characteristics for social and affective relations. In contrast, the men exhibited disinterest in acting constructively in their medium, temperament characteristics linked to nonconformity and impulsiveness, and moods typified by indifference, dislike and vulnerability [37].

These differences in self-concept by sex are apparently the result of learned cultural models and adaptation to the social medium. Social or cultural models are defined stereotypes based on societal expectations of what one should be or do [46] These stereotypes influence individual identity construction, particularly in adolescence when differences between men and women become patent. Some researchers describe adaptation strategies as a s et of cognitive and affective factors that manifest in actions that allow young people to solve problems [47]. Men and women differ in their strategies: women employ social networks, the expression of feelings, cooperation, and are more affective, assertive, social and resilient; men tend to be more rational, active and aggressive.

\section{Age}

Differences by age were only present in the socialemotional intelligence factor of the self-concept dimension, and the natural juice intake item in the eating habits dimension. The social-emotional intelligence factor refers to the way an individual confronts interpersonal relations and problems. Difference by age in this factor is a manifestation of maturation with age since the older students perceived themselves as calmer, more serene, peaceful, relaxed and stable [37]. The difference in natural juice intake shown with the ANOVA disappeared when the Tamhane test was applied since variance heterogeneity prevented any possible differences.

\section{CONCLUSION}

Education is considered to be one of the variables which most affects human wellbeing, especially among the poor. The education available to high school students in the poor rural area of Yaxcaba, Yucatan, has had only a partial impact on their wellbeing in the form of slightly improved eating habits. However, the vital dimension of self-concept was little changed. The present results largely contradict reports that education influences aspects of wellbeing such as selfconcept. Age expressed in terms of semesters completed had a positive effect in that high-fat and high-sugar foods were not consumed as regularly among older students. Clearly, education in the studied school is focused primarily on knowledge acquisition, with minimal attention given the values and attitudes that directly impact student wellbeing. The low impact of education on student wellbeing highlights the need for greater emphasis on fundamental behavioral aspects such as healthy eating habits and positive self-concept. The overall goal should be for graduates to have an integral education that allows them to live a satisfying life.

Sex had a clear impact on eating habits and self-concept. Given that these differences are at least partially due to traditional sociocultural aspects and that formal education is vital in transmitting social values, greater effort needs to be made to transmit respect and equality among women and men. This should be a basic element in Mexico's educational system since the country has accepted the challenge of providing education for life at all grade levels. In addition to basic knowledge, this approach promotes values and attitudes that produce better citizens who take an interest in their health and that of the environment; who are responsible and respectful; who work collaboratively; who have positive selfvalue; and are motivated to succeed. If this goal is achieved, Mexico may become a better country both now and in the future.

\section{ACKNOWLEDGMENT}

The authors thank the students of the Yaxcaba COBAY and the Academic Director of the COBAY.

\section{REFERENCES}

[1] Bloom, D. E. (2005). Education and Public Health: Mutual Challenges Worldwide. Comparative Education Review. 49(4):437-451. Accessed 28 March $2013 \quad$ at http://www.bvsde.paho.org/bvsacd/cd66/ubase edu health dev.pdf

[2] Newton, H. (2008). Teaching Health and Sex Education. Research Starters- Education. 1-9.

[3] CEPAL (2008). Superar la pobreza mediante la inclusión social. Accessed $\quad 28 \quad$ March $2013 \quad$ at http://www.eclac.org/publicaciones/xml/8/32358/dp_lcw174.pdf

[4] Ordaz Diaz J. L. (2009) México: impacto de la educación en la pobreza rural. CEPAL. Sede Subregional México. Estudios y Perspectivas 105. Pg. 40. Accessed 28 March 2013 at http://www.eclac.cl/publicaciones/xml/4/35044/Serie_105.pdf

[5] Wigley, S. \& Akkoyunlu-Wigle, A. (2006). Human Capabilities versus Human Capital. Social Indicators Research. 78(2): 287-304

[6] Lanzi, D. (2007). Capabilities, human capital and education. Journal of Socio-Economics 36, 424-435.

[7] González-Mora, G. (2001). Educación para la vida: el gran reto. Revista Latinoamericana de Psicología. 33: 73-84.

[8] OECD .(2003).The Definition and Selection of Key Competencies: Executive Summary. Organisation for Economic Co-operation and $\begin{array}{lllll}\text { Development. } \quad \text { Accessed } & 19 & \text { October } & 2009 & \text { at }\end{array}$ http://www.oecd.org/dataoecd/47/61/35070367.pdfking

[9] UNICEF (2009). Educación práctica para la vida. Updated: 21 May 2009. Accessed $27 \quad$ March 2013 at http://www.unicef.org/spanish/education/index_focus_lifeskills.html

[10] CEPAL (2010). La educación frente a la reproducción intergeneracional de la desigualdad y la exclusión: situación y desafíos en América Latina. 
Accessed $\quad 27 \quad$ March 2013 http://www.eclac.org/publicaciones/xml/9/41799/PSE2010-Cap-IIeducacion-preliminar.pdf

[11] Desjardins, R. (2008). Researching the Links between Education and Well-being. European Journal of Education. 1 (43), 23-35.

[12] Cuanalo de la Cerda, H. (2003). Un Modelo de Desarrollo Sustentable. Pp. 7 to 24. In H. Cuanalo de la Cerda. Ed. Desarrollo Social Contra la Pobreza. México. Red Mexicana de Proyectos de Desarrollo Social. Cinvestav. Unidad Mérida y Fundación W. K. Kellogg.

[13] Nussbaum, M. \& Sen, A. (2004). La calidad de vida. México: Fondo de Cultura Económica.

[14] Palomar, J. (2004). Poverty and Subjective Well-being in Mexico. Social Indicators Research. 68:1-33.

[15] Palomar, J. (2001). La pobreza y el bienestar subjetivo en los rostros de la pobreza. El debate. Guillardo, L. \& Osorio, J. (Cord.). México: Limusa. pp. 189-219.

[16] Branden, N. (2001). La psicología de la autoestima. México: Paidós.

[17] Max-Neef, M., Elizalde, A. \& Hopenhayn, M. (1986). Desarrollo a Escala Humana. Accessed 28 March 2013 at http://www.dhf.uu.se/pdffiler/86_especial.pdf

[18] Ayala, L. \& Perez-Mayo, A. (2011). Income Poverty and Multidimensional Deprivation: Lessons from Cross-Regional Analysis. Review of Income and Wealth. 57(1): 40-60. World Bank (2004). La pobreza en México. Una evaluación de las condiciones, las tendencias y la estrategia del gobierno. Accessed 28 March 2013 at http://siteresources.worldbank.org/INTMEXICOINSPANISH/Resources b resumen.pdf

[19] UN, (2009). Report on the World Social Situation 2010, Rethinking Poverty. Accessed 23 March 2013 at http://www.un.org/esa/socdev/rwss/docs/2010/fullreport.pdf

[20] CONEVAL (2010). Informe de Pobreza Multidimensional en México, 2008. Accessed $30 \quad$ May $2011 \quad$ at http://www.coneval.gob.mx/cmsconeval/rw/resource/coneval/med_pobr eza/Informe pobreza_multidimensional/Informe de Pobreza_Multidim ensional_en_Mexico_2008.pdf?view=true

[21] Cuanalo de la C. H. E. (2007). Desarrollo social contra la pobreza como un sistema complejo. $\mathrm{X}$ Congreso Internacional de Agricultura Sostenible. V Congreso Nacional De Agricultura Sostenible. II Coloquio en Agroecosistemas Sostenibles. CD. Pp.46-59. World Trade Center. Boca del Rio, Veracruz, México. Invited paper.

[22] White, S. C. (2009). Wellbeing in development practice. Wellbeing Development Countries Working paper No. 50. Accessed 28 March $2013 \quad$ at: $\quad$ http://www.welldev.org.uk/wednew/workingpapers/workingpapers/WeDWP 09_50.pdf

[23] White, S. \& Pettit, J. (2004). Participatory Approaches and the Measurement of Well-being". Wellbeing Development Countries Working paper No.8: Accessed 28 March 2013 at http://www.welldev.org.uk/research/workingpaperpdf/wed08.pdf

[24] McGregor, J. A. (2006).WeD Working Paper No. 20: 'Researching wellbeing: From concepts to methodology'. Accessed 28 March 2013 at http://www.welldev.org.uk/research/workingpaperpdf/wed20.pdf

[25] Camfield, L., Choudhury, K \& Devine, J. (2006). WeD Working paper No. 14: 'Relationships, Happiness and Wellbeing: Insights from Bangladesh'. Accessed 28 Marh 2013 at http://www.welldev.org.uk/research/workingpaperpdf/wed14.pdf

[26] White, S. \& Ellison, M. (2006). Wellbeing, livelihoods and resources in social practice. Wellbeing Development Countries Working paper No.23. Accessed 28 March 2013 at http://www.welldev.org.uk/research/workingpaperpdf/wed23.pdf

[27] Casas, F., Figuer, C., González, M., Malo, S., Alsinet, C. \& Subarroca, S. (2007). The Well-being of 12 to 16 year-old adolescents and their parents: results from 1999. Social Indicators Research 03: 87-115

[28] Tomlinson, M. and Walker, R., 2010. Poverty, adolescent well-being and outcomes later in life International Journal of Development, Special Issue: Children and Young People in a Changing World Volume 22, Issue 8, pages 1162-1182.

[29] Konu, A. et al. (2002). Well-being in schools: a conceptual model. Health Promotion International. 17: 79 - 87.
[30] Wills, E. (2009). Spirituality and Subjective Well-Being: Evidences for a New Domain in the Personal Well-Being Index. Journal of Happiness Studies 10(1): 49-69.

[31] Berger, C. (2009). Bienestar socio-emocional en contextos escolares: la percepción de estudiantes chilenos. Estudios Sobre Educación. 17:21-43

[32] Cardamone, D. \& Shannon, B. Influences on adolescent eating behavior Journal of Adolescent Health. 18: 27-34.

[33] Ortiz-Hernández, L. \& Gómez-Tello, B. (2008). Food consumption in Mexican adolescents. Revista Panamericana de Salud Publica. 24(2):127-35

[34] Story, M., Neumark-Sztainer, D. \& S.French (2002). Individual and environmental influences on adolescent eating behaviors. The American Dietetic Association. 120(3): 40-51.

[35] Rivera, JA., Juan A Rivera, Muñoz-Hernández,O., Rosas-Peralta, M., Aguilar-Salinas, C., Popkin, MB., Willett. (2008). Consumo de bebidas para una vida saludable: recomendaciones para la población mexicana. Salud Pública de México. 50(2): 173-195. Accessed 28 March 2013 at http://www.medigraphic.com/pdfs/salpubmex/sal-2008/sal082j.pdf

[36] Story, M., Neumark-Sztainer, D. \& French, S.(2002). Individual and environmental influences on adolescent eating behaviors. The American Dietetic Association. 120(3): 40-51.

[37] Díaz-Loving, R., Reyes lagunes, I. \&Rivera Aragón, S. (2002) Autoconcepto: desarrollo y validación de un inventario etnopsicológico. Revista Iberoamericana de Diagnóstico y Evaluación Psicológica 13(1): $29-54$.

[38] Kokkinos, C. \& Hatzinikolaou,S. (2001). Individual and contextual parameters associated with adolescents' domain specific self perceptions. Journal of Adolescence. 34(2): 349-360.

[39] INEGI (2011). Censo de Población y Vivienda 2010, Yaxcabá, Yucatán. Accessed $26 \quad$ March 2013 at http://www.inegi.org.mx/sistemas/mexicocifras/default.aspx?ent=31\&m un $=104 \&$ src $=487$

[40] Reyes-Lagunes \& Hernández-Manzo (1998). Escala de Autoconcepto. In: Rivas-Dawn P. E. 2011. La educación y el bienestar de los estudiantes de un bachillerato en una zona rural pobre de Yucatán. Anexo 1. Pp. 67-69. Master of Sciences Thesis. Cinvestav - Mérida. $\begin{array}{lllll}\text { Accessed } & 7 & \text { May } & 2012 & \text { at }\end{array}$ http://www.mda.cinvestav.mx/ecohum/tesis estudiantes/TesisPRivas11. pdf.

[41] FAO (2001). Human energy requirements. Report of a Joint FAO/WHO/UNU Expert Consultation. Accessed 28 March 2013 at ftp://ftp.fao.org/docrep/fao/007/y5686e/y5686e00.pdf

[42] Wardle, J., Haase, AM., Steptoe, A., Nillapun, M., Jonwutiwes, K. \& Bellisie, F. (2004). Gender differences in food choice: The contribution of health beliefs and dieting. Annals of Behavioral Medicine. 27(2): 107116. Accessed $28 \quad$ March 2013 at http://www.springerlink.com/content/n35353578760x4q1/fulltext.pdf

[43] Inglés, C., Pastor, Y., Torregrosa, M., Redondo, J. \& García-Fernández, JM. (2009). Diferencias en función del género y el curso académico en dimensiones del autoconcepto: estudio con una muestra de adolescentes españoles. Anuario de Psicología. 40 (2): 271-288. Accessed 5 June 2010 at http://redalyc.uaemex.mx/redalyc/pdf/970/97017660009.pdf

[44] Kokkinos, C. \& Hatzinikolaou,S. (2001). Individual and contextual parameters associated with adolescents' domain specific self perceptions. Journal of Adolescence. 34(2): 349-360

[45] Shepherd, J. (2006).Young people and healthy eating: a systematic review of research on barriers and facilitators. Health Education Research. 21(2): 239-257. Acessed 28 March 2013 at http://her.oxfordjournals.org/content/21/2/239.full.pdf

[46] Athenstaedt, U., Haas, E. \& Schwab, S. (2004). Gender Role SelfConcept and Gender-Typed Communication Behavior in Mixed-Sex and Same-Sex Dyads. Sex Roles. 50: 37-52.

[47] Frydenberg, E. \& Lewis, R. (1993). Boys play sport and girls turn to others: age, gender and ethnicity as determinants of coping. Journal of Adolescence: 16: 253-266.

\section{Creative Commons Attribution License 4.0 (Attribution 4.0 International, CC BY 4.0)}

This article is published under the terms of the Creative Commons Attribution License 4.0 https://creativecommons.org/licenses/by/4.0/deed.en_US 